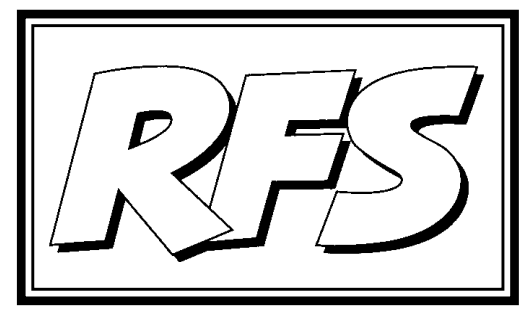

Revista de Fomento Social, 60 (2005), 119-126

\title{
La herencia de monseñor Romero
}

Bartolomeo SORGE S.J. ${ }^{1}$

(Palabras clave: Biografía, Teología de la Liberación, Concllo Vaticano II)

(Key WoRds: BIoGRAPHY, LIBERATION THEOLOGY, SECOND VATICAN COUNCIL)

Hace 25 años, el 24 de marzo de 1980, Óscar Arnulfo Romero, arzobispo de San Salvador, caía asesinado sobre el altar por los disparos de los "escuadrones de la muerte", sicarios de una extrema derecha fuerte y despiadada. Habiéndolo conocido personalmente, permítaseme, antes que nada, un breve testimonio, para después evocar el mensaje de este mártir de los nuevos tiempos.

1 Director de Aggiornamenti Sociali. Artículo editorial aparecido en dicha revista en el número correspondiente a marzo de 2005, pp. 177-182. Agradecemos su permiso para reproducir este texto en nuestra revista. Traducción del original italiano de la redacción de la Revista de Fomento Social. 


\section{Así lo recuerdo}

Conocí a monseñor Romero en Puebla, en México. Yo era director de $L a$ Civiltà Cattolica, y Juan Pablo I (cuya muerte imprevista hizo retrasar tres meses el evento) me envió como "experto" a la III Conferencia General del Episcopado Latinoamericano (22 de enero a 16 de febrero de 1979). Fui asignado a la Comisión VI, encargada de estudiar la relación entre evangelización, liberación y promoción humana; la Comisión estaba formada por diecisiete miembros, entre los que se encontraban monseñor Romero y monseñor Helder Câmara. No fue, por tanto, un encuentro fortuito, ni fugaz. De hecho, trabajamos juntos durante tres semanas, para profundizar el discurso sobre la nueva evangelización en América Latina, a la luz de la palabra de Dios, de la enseñanza de la Iglesia y de las urgencias de los pobres.

Al llegar a Puebla, llevaba conmigo el prejuicio, difundido en el ambiente romano, según el cual monseñor Romero era un "cabeza caliente", un obispo "politizado", defensor de la "teología de la liberación". Tras el primer encuentro descubrí, en cambio, un Romero completamente diferente. Me impresionaron rápidamente la humildad de su trato, su espíritu de oración, la indiscutida fidelidad al Evangelio y a la Iglesia, sobre todo el gran amor por los pobres, por sus campesinos ${ }^{2}$. Durante las intensas semanas de trabajo común, me quedé impresionado especialmente por su disponibilidad. Le vi renunciar más de una vez a su parecer, dejándolo caer sin insistir, cuando la mayoría de la Comisión se inclinaba por otra solución o por una formulación diferente.

En particular, me pareció totalmente infundada la acusación de ser partidario de la "teología de la liberación". Yo conocía bien las nuevas corrientes teológicas de América Latina, porque nos habíamos ocupado de ellas también en La Civiltà Cattolica. De modo que me di cuenta en seguida de que Romero no era en absoluto condescendiente con los enfrentamientos de las posiciones extremas de algunos teólogos; en realidad, al denunciar la injusticia, no hacía sino aplicar la Palabra de Dios a los problemas concretos de la gente. Era, pues, un error confundir las desviaciones teológicas de los "cristianos por el socialismo" o de la "lectura materialista del Evangelio" con la lectura profética y con la aplicación sapiencial que Romero y otros obispos latinoamericanos hacían de la Palabra de Dios.

Recuerdo las agradables conversaciones durantelos intervalos. Me dijo que

2 En castellano en el original (N. del T.). 
había sido enviado a San Salvador, porque tenía fama de "conservador", para "reequilibrar" una situación eclesial difícil. En particular, un día, durante la pausa de media mañana, me contó la situación dolorosa y dramática del país, de los derechos humanos pisoteados, de las "desapariciones" de tantos de sus hijos, de las torturas y de las ejecuciones sumarias, del clima violento de represión que estaba empujando a El Salvador hacia la insurrección popular (así lo temían). Sin embargo no tenía ni una sola palabra de odio o de rabia; creía firmemente que se debía detener la violencia, viniera de donde viniera; decía que la venganza debía ser desterrada y, por el contrario, debían triunfar la justicia y el amor para conducir a la reconciliación y a la paz.

Puedo añadir que la opción preferencial por los pobres había llegado a ser para él una razón de vivir. Y me contó su "conversión":

Cuando asesinaron a mi brazo derecho, el padre Rutilio Grande-me dijo-los campesinos se quedaron huérfanos de su padre y de su más ferviente defensor. Fue durante la vigilia de oración ante los restos del heroico padre jesuita, inmolado por los pobres, cuando me di cuenta que ahora me tocaba a mí tomar su lugar, bien consciente de que así también yo me estaría jugando la vida.

En un determinado momento -lo recuerdo bien- se interrumpió; y, cambiando de tono, añadió textualmente: "He sabido hace poco de que acaban de matar a mi cuarto sacerdote. Lo sé. En cuanto me cojan, me van a matar". Lo esperaba. No daba señal de pesadumbre ni de miedo. Sonreía. De su rostro se transparentaba una serenidad que sólo un gran amor podía dar. No lo he olvidado nunca. Era el rostro de un mártir de los nuevos tiempos. La "profecía" se realizó puntualmente el año siguiente, cuando cayó como víctima inmolada sobre el altar.

\section{2. ¿"Conversión” o "evolución”?}

También monseñor Romero tuvo su evolución. Cuando en 1977 fue nombrado arzobispo de San Salvador se pudo decir que él era sustancialmente un "conservador": fiel a la institución eclesiástica, moderado en política, sensible a los problemas sociales, preocupado por la extensión del fenómeno de la politización del clero. Tanto, que llegó a enfrentarse con los "jesuitas jóvenes" prendados de la teología política, con los padres de la Universidad Centroamericana (UCA) y con su Provincial, acusándolos de politizar las instituciones educativas de la Compañía. ¿Qué le sucedió después a Romero?

Se discute si su "conversión" fue imprevista. En realidad, una atenta lectura de su biografía no autoriza a realizar una separación neta entre un antes y 
un después, entre el Romero conservador y el arzobispo de San Salvador progresista, amigo del pueblo y alineado con los pobres. Por este motivo, "conversión" es un término impropio, que el propio Romero refutaba. Sin embargo, es imposible negar el influjo determinante que el asesinato del padre Rutilio Grande, ocurrido el 12 de marzo de 1977, a pocos días de su llegada a la diócesis, tuvo sobre el nuevo arzobispo. Él mismo solía hablar de cambio radical en su vida.

Pero prefería decir que, gracias al sacrificio del padre Rutilio, Dios le había concedido un particular don de "fortaleza pastoral", capaz de hacerle afrontar con valentía conflictos y persecuciones, sin vacilar ante el drama de los sacerdotes, catequistas y fieles torturados y asesinados, sin arredrarse ante las divisiones lacerantes que rompían al país y a la Iglesia salvadoreña. De ahí que no se tratara de un golpe de rayo, sino de una maduración en la conciencia, como le confió en un escrito a Juan Pablo II, a poco de ser elegido pontífice.

He creído en conciencia que Dios me elegía y me daba una especial fortaleza pastoral que contrastaba con mi temperamento y mi inclinación "conservadora". He creído un deber ponerme decisivamente en defensa de mi Iglesia y, de la Iglesia, al lado de mi pueblo tan oprimido ${ }^{3}$.

En conclusión, del examen desapasionado de los documentos y de los testimonios se debe concluir que la muerte del padre Rutilio Grande fue para monseñor Romero la ocasión para asumir una más plena responsabilidad apostólica, a la que sin embargo él estaba ya espiritualmente preparado; el asesinato del jesuita le proporcionó un nuevo coraje para el testimonio y para el anuncio del Evangelio en una comunidad eclesial profundamente dividida y en un país en aquel momento ya en clima de abierta persecución. La confirmación de la autenticidad de la gracia recibida se puede atisbar en el hecho de que el arzobispo no hizo suya la elección de la violencia, sino que insistía siempre sobre la fuerza liberadora del amor cristiano, hasta la última entrevista aparecida poco después de ser asesinado:

La Iglesia -se lee- ha condenado siempre la violencia como fin en sí mismo o usada abusivamente contra los derechos humanos, o bien como primero y único medio para defender y afirmar un derecho humano. No se puede hacer un mal para conseguir un bien ${ }^{4}$.

3 Morozzo della Rocca R., (2005), "Primero Dios”, Vita di Oscar Romero, Milano, Mondadori, p. 153.

4 Ib., p. 170. 
En una palabra, Romero fue siempre coherente con las orientaciones del Concilio Vaticano II y del magisterio de la Iglesia: de un lado, no desdeñó las devociones clásicas, preocupado por llevar a los fieles desde una religiosidad popular (que a veces se acerca a la superstición) a una fe madura; por otro, estaba convencido de que, en la dramática emergencia social y política en que se encontraba El Salvador, el único punto de referencia debería ser el Evangelio. La "equivocación" de monseñor Romero, que le atrajo incomprensiones y acusaciones durísimas también en el seno de la Iglesia, fue precisamente esto: que un arzobispo, hombre de la institución eclesiástica, en la confrontación con el poder político, se refiriese proféticamente al Evangelio más que al "poder" de la Iglesia. Ello le permitió hablar siempre con libertad y franqueza evangélica, como demuestran las famosas predicaciones dominicales en la misa de ocho, en las que, después de haber comentado la Palabra de Dios, confrontaba las enseñanzas con la situación del país. Esta ósmosis entre Palabra de Dios e historia es característica de la homilética de monseñor Romero: "No estamos hablando a las estrellas", le gustaba repetir.

No podemos separar la Palabra de Dios de la realidad histórica en que se pronuncia; de otra forma, la Biblia sería un libro devoto, como un libro de nuestra biblioteca; pero es la Palabra de Dios porque anima, ilumina, contrasta, repudia, elogia cuanto acontece hoy en nuestra sociedad 5 .

Obviamente, ese continuo encarnar la fe en los dramas y en la vida concreta del pueblo salvadoreño podía ofrecer el flanco a una fácil instrumentalización. Y, de hecho, no pocos se aprovecharon de ello. Sin embargo, no fue posible oscurecer la limpieza del servicio pastoral de monseñor Romero.

El corazón de mi vida -confiará al cardenal Baggio, prefecto de la Congregación para los obispos-es testimoniar el amor de Dios a los hombres y de los hombres entre sí. Esto se debe manifestar mediante nuestra propia vida y conducta de cristianos, con un testimonio visible de fidelidad a Jesucristo, de pobreza y de despego de los bienes materiales, de libertad ante los poderes de este mundo. En una palabra: de santidad ${ }^{6}$.

\section{Su herencia pastoral}

Las conclusiones del trabajo elaborado en Puebla en la V Comisión se encuentran condensadas en la II parte del Documento final, en particular en el párrafo no 4 del capítulo II, titulado "Evangelización, liberación y promo-

\footnotetext{
5 Ib., p. 223.

6 Ib., p. 220.
} 
ción humana"7. Sin forzar las cosas, podemos afirmar que aquellos párrafos, en cuya elaboración participó también Romero, ilumina la que podría ser llamada su herencia pastoral.

En particular, es significativo el juicio equilibrado sobre la "teología de la liberación". Romero prefería hablar de "liberación integral", para evitar que "liberación" sin adjetivo indujese a pensar en la sola dimensión política del compromiso cristiano. Es necesario -insistía- subrayar la concepción original de la liberación cristiana que es una síntesis entre evangelización y promoción humana. Es el mismo concepto que se encuentra en el citado párrafo $\mathrm{n}^{\mathrm{0}} 4$ :

Son dos elementos complementarios e inseparables: la liberación de todas las esclavitudes del pecado personal y social, de todo lo que hiere al hombre y a la sociedad y tiene su fuente en el egoísmo, en el misterio de iniquidad; $y$ la liberación por el crecimiento progresivo del ser por la comunión con Dios y con los hombres, que culmina en la perfecta comunión del cielo, donde Dios será todo en todos y no habrá más llanto. Es una liberación que se va realizando en la historia, sea en la de nuestros pueblos, sea en lo personal, y que abraza las diferentes dimensiones de la existencia: social, política, económica, cultural, y el conjunto de las relaciones. En todo esto debe circular la riqueza transformadora del Evangelio, con su aportación propia y específica que hay que salvaguardar .

Además, Romero estaba profundamente convencido de otro punto, sobre el que insiste el documento final de Puebla: no sólo los obispos y el clero, sino "toda la comunidad cristiana está llamada a hacerse responsable de las opciones concretas y de su efectiva realización para responder a las interpelaciones que presentan las circunstancias mudables"; en particular, "los laicos no deben ser ejecutores pasivos, sino colaboradores activos de los pastores, a los que aportan su experiencia y competencia profesional y científica ${ }^{9}$.

Ciertamente, la redacción del documento fue una obra común, pero es evidente la coincidencia ente las conclusiones de Puebla y la herencia pastoral de monseñor Romero.

De ahí que sorprenda mucho que algunos hayan podido dudar del amor a la Iglesia y de la fidelidad al Evangelio de un pastor para el cual la expresión ignaciana "sentir con la Iglesia", más que un lema escogido con ocasión de su

\footnotetext{
7 Cfr., (1979), Puebla. Comunione e partecipazione, Roma, AVE, nn. 470-506, pp. 594-602.

$8 \quad$ Ib., nn. 482s, p. 597.

9 Ib., n. 473, p. 395.
} 
ordenación episcopal, fue un auténtico programa de vida; hoy sigue siendo una parte esencial de su herencia espiritual. El quería que la composición gráfica del blasón episcopal pusiese en evidencia los elementos esenciales de su "sentir con la Iglesia". Así lo explica él mismo:

En el campo superior: sobre fondo azul, la palma de la Virgen de la Paz, patrona de nuestro país, mi principal devoción mariana. En el campo intermedio: sobre cuadrados amarillos y blancos, símbolo de la bandera de la Iglesia, la cruz papal que indica mi solidaridad con la Iglesia y el sucesor de Pedro con su triple potestad profética, sacerdotal y regia. Y debajo, sobre fondo blanco, un ramo de romero, mi apellido, una hierba significativa que perfuma, purifica, signo de mi deseo de prestar un sincero servicio personal a la Iglesia. En el fondo se ve el báculo, símbolo del pastor ${ }^{10}$.

Vivió los diez años de su episcopado (1970-1980) en la convulsa etapa postconciliar. Como suele suceder, en convergencia con los grandes cambios de la historia, también en el interior de la Iglesia se crean no pocas tensiones entre lo viejo que se resiste a morir y lo nuevo que le cuesta nacer. En tales transiciones difíciles, los verdaderos protagonistas del cambio no son -como erróneamente se tiende a pensar- los "innovadores" infatuados de lo nuevo, ni los "conservadores" preocupados de la fidelidad al pasado. En tales trances, los que verdaderamente hacen progresar y crecer a la Iglesia y a la sociedad son los hombres como Romero, "hombres de la síntesis", esto es, capaces de innovar en la fidelidad, de mediar entre lo viejo y lo nuevo, evitando las derivas opuestas del progresismo y del integrismo.

Es significativo, en esta línea, lo que escribía Romero en 1965, al final del Concilio:

La Iglesia está en un momento de "aggiornamento", esto es de crisis de su historia. $Y$ como todos los "aggiornamenti" emergen dos fuerzas antagonistas: de una parte, un afán desmesurado de novedad, definido por Pablo VI como "sueños arbitrarios de renovaciones artificiosas"; $y$, por otra parte, un apego a la inmovilidad de las formas adoptadas por la Iglesia a lo largo de los siglos, y el rechazo de la índole de los nuevos tiempos. Los dos extremos pecan de exageración. La adhesión incondicionada a lo viejo frena el proceso de la Iglesia y restringe la "catolicidad", que tiene un sentido no sólo geográfico sino también histórico y la hacen capaz de estar a tono con todas las ciudades y todas las épocas. El espíritu desmesurado de novedad es una imprudente exploración de lo incierto y, al mismo tiempo, traiciona injustamente el rico patrimonio de experiencias del pasado (...). Para no caer en el ridículo de una acrítica afición a lo viejo, y para no caer en el ridículo de hacerse aventureros de "sueños artificiosos" de novedad, es mejor vivir hoy más que nunca aquél clásico axioma: Sentir con la Iglesia $^{11}$, que concretamente significa respeto incondicionado a la jerarquía. Porque

10 Morozzo della Rocca, R., “Primero Dios”, cit., p. 382, nota 8.

11 En castellano en el original (N. del T.). 
son el Papa y los obispos los hombres inspirados por Dios para el "aggiornamento" de la Iglesia en todas las horas de su historia ${ }^{12}$.

Este "sentir con la Iglesia", entendido como síntesis entre novedad y continuidad, entre coraje profético y fidelidad a la institución eclesiástica, es el corazón de la herencia que Romero ha dejado no sólo a su comunidad salvadoreña, sino a la Iglesia entera.

$$
* * *
$$

Él sabía que estaba en el punto de mira de sus asesinos: sólo que no conocía la hora ni el modo en que lo habrían de matar. Las palabras conclusivas de su última homilía, en la tarde del 24 de marzo de 1980, dan el sentido de toda su vida apostólica:

Por la fe cristiana sabemos que en este momento la hostia de trigo se convierte en el cuerpo del Señor ofrecido para la redención del mundo y el vino que hay en este cáliz se transforma en sangre prenda de salvación. Que este cuerpo inmolado y esta sangre sacrificada por los hombres nos alimente también para dar nuestro cuerpo y nuestra sangre al sufrimiento y al dolor, como Cristo, no para sí, sino para dar frutos de justicia y de paz a nuestro pueblo ${ }^{13}$.

Apenas había terminado de pronunciar estas frases, un disparo de fusil al pecho las transformaba en su testamento espiritual: amar a Dios sobre todas las cosas (primero Dios) ${ }^{14}$ y amarnos los unos a los otros como Cristo nos ha amado, hasta dar la vida por los hermanos. ¿Qué otra cosa ha de ocurrir para reconocer la santidad de un heroico pastor que el pueblo ya aclama como "san Romero de las Américas"15?

\footnotetext{
12 I., pp. $73 \mathrm{s.}$

13 Ib., pp. 345 s.

14 En castellano en el original (N. del T.).

15 En castellano en el original (N. del T.).
} 